\title{
Analisa Algoritma String Matching Dan Winnowing Untuk Deteksi Kemiripan Judul Tugas Akhir Perguruan Tinggi
}

\author{
Lilik Sugiarto, Cisde Mulyadi, Siti Rihastuti \\ Amikom Solo \\ Lilik@dosen.amikomsolo.ac.id
}

\begin{abstract}
Abstrak
Judul Tugas akhir merupakan gambaran awal dari sebuah isi suatu dokumen, dimana judul merupakan arah awal dari sebuah isi suatu penelitian, Dimana terdapat kemiripan tugas akhir dengan isi yang diduga mirip dengan tugas akhir yang sudah pernah ada. Untuk pendeteksian awal sebuah Judul tugas akhir ada beberapa metode ataupun algoritma diantaranya String Matching Dan winnowing. Adapun Algoritma Winnowing merupakan salah satumetodeuntuk mendeteksi kesamaan (common subsequence). Duateks diketahui memiliki kesamaan kata/kalimat apabila didalam dokumen tersebut dijumpai fingerprint, fingerprint inilah yang akan dijadikan dasar pembanding antara teks, dimana nilai fingerprint diperoleh darin-grammengubahtekskedalamnilaiangka \{ hash\}. Sedangkan string Matching suatu metode pencocokan teks dengan langkah Memindai teks dengan bantuan sebuah finger yang ukurannya sama dengan panjang pattern kemudian Menempatkan window pada awal teks dan Membandingkan karakter pada window dengan karakter dari pattern. Setelah pencocokan dilakukan pergeseran ke kanan pada window. Prosedur ini dilakukan berulangulang sampai window berada pada akhir teks. Mekanisme ini disebut mekanisme sliding window. Analisa kedua metode baik string matching maupun winnowing akan dapat diketahui metode manakah yang lebih efektif dan efisien dalam deteksi dini kemiripan sebuah judul Tugas Akhir.
\end{abstract}

Kata kunci: Algoritma, Winnowing, String Matching, Pattern, Fingerprint, hash, Window

\begin{abstract}
The title of thesis is an initial description of the contents of a document, where the title is the initial direction of the contents of a research, there is a similarity between the final project and the content that is thought to be similar to an existing final project. For the early detection of a title, there are several methods or algorithms, including string matching and winnowing. The winnowing algorithms is a method for detecting similarities (common sub sequence). Two texts are known to have similar words or sentences if fingerprint are found in the document. This Fingerprint will be used as a basis for comparison between texts, where the fingerprint value obtained from $n$-grams converts the text into numeric values \{hash\}. Whereas string matching is a text matching method with the step of scanning text with the help of a finger whose size is the same as the length of the pattern then placing the window at the beginning of the text and comparing the characters in the window with the characters from the pattern. After matching is done shift right on window. This procedure is repeated until the window is at the end of the text. This mechanism is called sliding window. Analysis of both methods, both string matching and winnowing, will be able to fine out which method is more effective and efficient in early detection of the similarity of a title in the final project.
\end{abstract}

Keywords : Algorithm, Winnowing, String Matching, Pattern, Fingerprint, hash, Window 


\section{PENDAHULUAN}

$\begin{array}{cccc}\text { Salah satu ciri dalam penerapan } \\ \text { teknologi } & \text { adalah dimana teknologi }\end{array}$ dapatmembantu dalam menyelesaikan permasalahan secara efektif dan efisien bagi penggunanya. Dalam perkembangannya khususnya dalam bidang teknologi informasi telah terbukti dengan diterapkanya teknologi informasi dapat membantu memecahkan berbagai permasalahan-permasalahan yang terjadi. Adapun bidang yang telah menerapkan teknologi khususnya teknologi informasi baik itu bidang Politik, Ekonomi, sosial, Budaya serta bidang pertahanan dan keamanan suatu negara. Bahkan bisa dikatakan salah satu ciri sebuah negara maju tercermin dalam seberapa besar tingkat penerapan teknologi khususnya Teknologi informasi. Hal inilah salah satu bukti bahwa penerapan teknologi salah satu cara dalam menyelesaikan permasalahan secara efektif dan efisian.

Dalam dunia pendidikan khususnya perguaruan tinggi penerapan teknologi informasi buakanlah suatu hal yang asing dewasa ini, bahkan peran teknologi informasi suatu perguruan tinggi teknologi informasi dijadikan suatu sarana yang vital dalam membangun civitas akademika yang berdaya saing antara perguruan tinggi yang satu dengan perguruan tinggi lain baik secara nasional maupun skala internasional.

STMIK AMIKOM SURAKARTA adalah salah satu perguruan tinggi di wilayah surakarta yang baru berkembang saat ini. STMIK AMIKOM SURAKARTA yang berlokasi di jalan Veteran Notosuman, Kel Singopuran, kec. Kartasura Kab. Sukoharjo Prop.Jawa Tengah di beberapa tahun belakangan ini sedang giat membangun sebuah sistem informasi akademik. Harapanya Pembangunan sistem infomasi ini dapat menjadi salah satu daya saing dengan perguruan tinggi yang lain, sesuai visi dan misi perguruan tinggi yaitu menjadi perguruan tinggi unggulan dalam bidang ilmu pengetahuan dan teknologi informasi tahun 2030. Adapun pengembangan layanan yang bebasis teknologi informasi yang sudah diterapkan pada STMIK AMIKOM SURAKARTA belum menyasar dalam hal layanan pengajuan judul Tugas akhir secara online. Penulis tertarik dengan koleksi tugas akhir di perpustakaan STMIK AMIKOM SURAKARTA diduga terdapat kemiripan judul, hal inilah menurut penulis akan berdampak buruk baik perkembangan ilmu pengetahuan itu sendiri maupun secara institusi yang disebabkan tugas akhir yang hanya membahas permasalahan yang sama sehingga kurangya khasanah keragaman judul Tugas Akhir.

Sebelum penerapan teknologi informasi pengajuan judul secara online ini diterapkan maka perlu adanya analisa lebih mendalam mengenai metode ataupun algoritma apa saja yang nantinya dapat digunakan dalam rancang bangun sebuah sistem informasi pengajuan judul tugas akhir berbasis web pada STMIK AMIKOM SURAKARTA. Kajian ini perlu dilakukan guna mengetahui metode apa yang tepat untuk mengatasi permasalahan ini dan salah satu dari.

Dalam kasus permasalahan ini penulis mencoba untuk membuat penelitian awal dengan menganalisa beberapa algoritma tentang perbandingan kata ataupun kalimat dengan algoritma STRING MATCHING dan WINNOWING untuk Deteksi awal kemiripan sebuah Tugas Akhir dengan harapan kedepan semakin banyak dan beraneka raga bahasan sebuah tugas akhir tentang teknologi informasi. Dengan ini penulis membuat penelitian yang berjudul ANALISA ALGORITMA STRING MATCHING DAN WINNOWING UNTUK DETEKSI KEMIRIPAN JUDUL TUGAS AKHIR PERGURUAN TINGGI.

Rumusan Masalah

Dalam penelitian ini dapat dirumuskan bahwa bagaimana Analisa Algoritma STRING MATCHING Dan Winnowing Untuk Deteksi Kemiripan Judul Tugas Akhir Perguruan Tinggiyang kedepanya dapat dijadikan sebuah acuan awal dalam rancang bangun sebuah sistem informasi tugas akhir secara online.

\subsection{Tujuan Penelitian}

Tujuan penelitian ini adalahmenerapkan ilmu bidang teknologi informasi danmengetahui beberapa algoritma dalam pembobotan guna mengetahui tingkat kemiripan sebuah kata ataupun kalimat yang natinya difokuskan untuk penilaian kemiripan judul tugas akhir

\section{METODE}

Pada penelitian yang diusulkan mengambil studi kasus diSTMIK AMIKOM SURAKARTA yang berlokasi di jalan Veteran Notosuman, Kel Singopuran, kec. Kartasura Kab. Sukoharjo 
Prop.Jawa Tengah, adapunMetode yang digunakan dalam penelitian ini adalah action research, yaitu bertujuan untuk mengembangkan pendekatan baru dalam memecahkan masalah dengan penerapan langsung di dunia nyata((Hasibuan, 2007)Hazibuan, 2007).

\subsection{Metode Pengumpulan Data}

Berdasarkan jenis datanyadata yang dikumpulkan dalam penelitian ini adalah sebagai berikut:

\subsubsection{Data Primer}

Data primer adalah data yang diambil langsung dari objek penelitian atau merupakan data yang berasal dari sumber asli atau pertama.Teknik pengumpulan data primer dilakukan melalui teknik observasi dan wawancara.

Untuk teknik observasi pada penelitian ini digunakan untuk mengetahui prosedur langkah kerja sistem pengajuan judul Tugas Akhir yang sudah berjalan. Serta memperoleh data tentang kendala-kendala dalam melakukan langkah kerja sistem pengajuan judul Tugas Akhir secara konvensional tersebut.

Teknik wawancara pada penelitian ini peneliti melakukan wawancara kepada pejabat pejabat yang berwenang yang sesuai dengan keahlian bidang Akademik pada STMIK AMIKOM SURAKARTA. Hal ini dilakukan untuk mendukung objek penelitian supaya hasil penelitian sesuai dengan yang diharapkan

\subsubsection{Data Sekunder}

Data sekunder adalah data yang tidak didapatkan secara langsung dari objek penelitian, melainkan data yang berasal dari sumber yang telah dikumpulkan dari pihak lain. Teknik pengumpulan data sekunder dilakukan dengan cara studi dokumentasi dan studi literatur.

\subsection{Metode Analisis Data}

\subsubsection{Algoritma String Matching}

String matching merupakan salah satu Algoritma pencarian sebuah kata ataupun kalimat yang biasa dikenal dengan istilah pencocokan string, cara kerja algoritma ini dalam menyelesaikan permasalahan pencocokan string dengan melakukan pencarian kemunculan string pendek yang dikenal dengan istilah pattern(0..n-1) dan sedangkan string yang lebih panjang yang disebutteks (0..m-1). Dalam teknik untuk memecahkan permasalahan pencocokan string ini terdapat beberapa algoritma diantaranya, Algoritma string matching Brute Force, Algoritma Rabin Karp, Algoritma Knout Morris Pratt dan AlgoritmaBoyer moore(Waruwu \& Mandala, 2016).

Dari beberapa algoritma string matchingdiatas pada dasarnya setiap algoritma memiliki kelebihan dan kekurangan masing-masing. Pada penelitian yang dilakukan(Waruwu \& Mandala, 2016)dapat disimpulkan dari kedua algoritma algoritma KMP (Knout Morris Pratt) dan algoritma Boyer Moore tersebut algoritma boyer moore diketahui membutuhkan waktu lebih cepat dalam akses pencocokan string". Dari hasil tersebut diatas penulis kecenderungan tertarik menggunakan algoritma KMP (Knout Morris pratt)dalam penyelesaian masalah pencocokan string dimana dengan algoritma tersebut memiliki beberapa kelebihan.

string matching dirumuskan dengan :

$$
\begin{aligned}
& x=x[0 \ldots m-1] \\
& y=y[0 \ldots n-1]
\end{aligned}
$$

Dimana:

$$
\begin{aligned}
& \mathrm{x}=\text { Pattern } \\
& \mathrm{m}=\text { panjang Pattern } \\
& \mathrm{y}=\text { teks } \\
& \mathrm{n}=\text { panjang teks }
\end{aligned}
$$

Menurut (Effendi et al., 2013) Prinsip kerja algoritma string matching adalah sebagai berikut :

1. Pemindaian Teks

Dalam algoritma string matching tahapan pertaman yaitun dengan Memindai teks dengan bantuan sebuah window yangukurannyasamadengan panjang Pattern. Dicontohkan algoritma Knouth morris pratt dalam pencocokan

$$
\begin{aligned}
& \text { Pattern = INFO } \\
& \text { Teks = SISTEM INFORMASI }
\end{aligned}
$$

2. Menempatkan window pada awal teks. Langkah berikutnya yaitu pencocokan digambarkan pada tabel 1.1 dibawah ini. Dimana data Pattern dan teks ditempatkan kedalam window yang nantinya akan dilakukan pergeseran atau dengan istilah sliding window. 
Tabel 3.1 langkah ke 1

\begin{tabular}{|c|c|c|c|c|c|c|c|c|c|c|c|c|c|c|}
\hline Pattern & & $\mathrm{N}$ & $\mathrm{F} / \mathrm{C}$ & & & & & & & & & & & \\
\hline Teks & $s$ & 1 & $\begin{array}{l}\mathrm{s} \\
\mathrm{s}\end{array}$ & 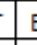 & $M$ & 1 & $\mathrm{~N}$ & $\mathrm{~F} C$ & $R$ & $\mathrm{M}$ & A & & & 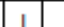 \\
\hline indek & 0 & 1 & \begin{tabular}{l|l}
2 & 3 \\
\end{tabular} & 4 & 5 & & & & & & & & & \\
\hline
\end{tabular}

Membandingkan karakter pada window dengan karakter dari Pattern. Setelah pencocokan dilakukan pergeseran ke kanan pada window.

Tabel 3.2 langkah ke 2

\begin{tabular}{|c|c|c|c|c|c|c|c|c|c|c|c|c|c|c|c|}
\hline Pattern & & 1 & $\mathrm{~N}$ & $\mathrm{~F}$ & 0 & & & & & & & & & & \\
\hline Teks & $S$ & 1 & $\mathrm{~S}$ & $T$ & $E$ & $M$ & 1 & $\mathrm{~N}$ & $\mathrm{~F}$ & 0 & $\mathrm{R}$ & $\mathrm{M}$ & $\mathrm{A}$ & $\mathrm{s}$ & \\
\hline indeks & & 1 & 2 & 3 & 4 & 5 & & 7 & 8 & 9 & & 11 & 12 & 13 & 14 \\
\hline
\end{tabular}

Tabel 3.3 langkah ke 3

\begin{tabular}{|c|c|c|c|c|c|c|c|c|c|c|c|c|c|c|c|}
\hline Pattern & & & 1 & $\mathrm{~N}$ & $\mathrm{~F}$ & 0 & & & & & & & & & \\
\hline Teks & $s$ & I & $s$ & $T$ & $\mathrm{E}$ & $\mathrm{M}$ & 1 & $\mathrm{~N}$ & $F$ & 0 & \begin{tabular}{l|l}
$R$ \\
\end{tabular} & $\mathrm{M}$ & $A$ & $s$ & 1 \\
\hline d & 0 & & 2 & 3 & 4 & -1 & 6 & 7 & 8 & 9 & 10 & & & & 1 \\
\hline
\end{tabular}

Tabel 3.4 langkah ke 4

\begin{tabular}{|c|c|c|c|c|c|c|c|c|c|c|c|c|c|c|c|}
\hline Pattern & & & & 1 & $\mathrm{~N}$ & $F$ & 0 & & & & & & & & \\
\hline reks & $s$ & I & S & $T$ & $E$ & $\mathrm{M}$ & I & $\mathrm{N}$ & $\mathrm{F}$ & 0 & $R$ & M & A & $\mathrm{s}$ & 1 \\
\hline deks & 0 & 1 & . & 3 & 4 & 5 & 6 & 7 & 8 & 9 & & & & & 14 \\
\hline
\end{tabular}

Tabel 3.5 langkah ke 5

\begin{tabular}{|c|c|c|c|c|c|c|c|c|c|c|c|c|c|c|c|}
\hline Pattern & & & & & 1 & $\mathrm{~N}$ & $F$ & 0 & & & & & & & \\
\hline Teks & $s$ & 1 & $\mathrm{~s}$ & $\mathrm{~T}$ & $\mathrm{E}$ & $\mathrm{M}$ & 1 & $\mathrm{~N}$ & $\mathrm{~F}$ & 0 & 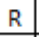 & $\mathrm{M}$ & A & $\mathrm{s}$ & 1 \\
\hline dek & & & & & & 5 & 6 & 7 & & 9 & & & & & 14 \\
\hline
\end{tabular}

Tabel 3.6 langkah ke 6

\begin{tabular}{|l|c|c|c|c|c|c|c|c|c|c|c|c|c|c|c|c|}
\hline Pattern & & & & & & I & N & F & O & & & & & & & \\
\hline Teks & S & I & S & T & E & M & I & N & F & O & R & M & A & S & I & \\
\hline Indeks & 0 & 1 & 2 & 3 & 4 & 5 & 6 & 7 & 8 & 9 & 10 & 11 & 12 & 13 & 14 & \\
\hline
\end{tabular}

Tabel 3.7 langkah ke 7

\begin{tabular}{|c|c|c|c|c|c|c|c|c|c|c|c|c|c|c|}
\hline Pattern & & & & & & & & & & & & & & \\
\hline Teks & $s$ & & $\mathrm{~s}$ & T & $\mathrm{E}$ & $\mathrm{M}$ & I & $\mathrm{N}$ & $\mathrm{F}$ & 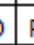 & $\mathrm{N}$ & $\mathrm{M} A \mathrm{~A}$ & & $5 \mid 1$ \\
\hline deks & 0 & 1 & 2 & 3 & 4 & 5 & 6 & 7 & 8 & & & & & \begin{tabular}{l|l}
3 & 14 \\
\end{tabular} \\
\hline
\end{tabular}

\subsubsection{Algoritma Winnowing}

Algoritma winnowing adalah salah satu algoritma pencocokan string dimana dalam pendekteksianya harus memenuhi kebutuhan mendasar (Astutik et al., 2014) yaitu

1. Whitespace insetivity yaitu pencarian kalimat yang tidak terpengaruh oleh spasi, jenis huruf( kapital atau normal), tanda baca dan sebagainya.

2. Noise supresion yaitu menghindari penemuankecocokan dengan panjang kata yang terlalu kecil atau kurang relevan seperti "the" dan bukan kata yang umum digunakan.

3. Position independece yaitu penemuan kesamaanharus tidak bergantung pada posisi kata-kata sehingga kata dengan urutan posisi berbeda masih dapat dikenali jika terjadi kesamaan.

Proses pengidentifikasian kemiripan sebuah dokumen dapat dilakukan dengan meggunakan algoritma Winnowing. Algoritma ini menggunakan metode document fingerprinting untuk medeteksi keakuratan salinan antar dokumen atau hanya sebagian teks.

Secara umum algoritma winnowing memiliki beberapa konsep dalam melakukan pendeteksian sebuah dokumen, berikut konsep kerja algoritma winnowing:

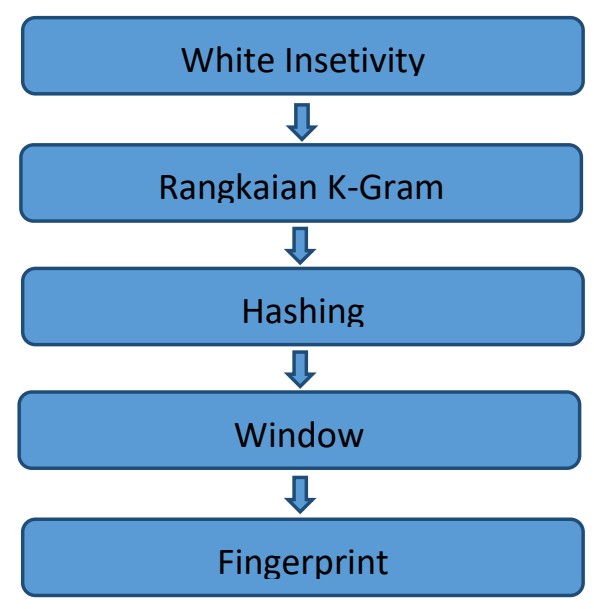

Gambar 3.1 konsep algoritma Winnowing .

3.2.2.1 Penghapusan karakter-karakter yang tidak relevan (whitespace insensitivity). Pada tahap Penghapusan karakter yang tidak relevan ini algoritma winnowing melakukan proses penghapusan tanda baca, spasi dan simbol atu karakter seperti !, @, \#, \$, \%, ^, \&, *, (, ), , - , +, <, $>$, ?berikut sebagai contoh:

E-commerce \& E-learning adalah bentuk aplikasi berbasis web!! 


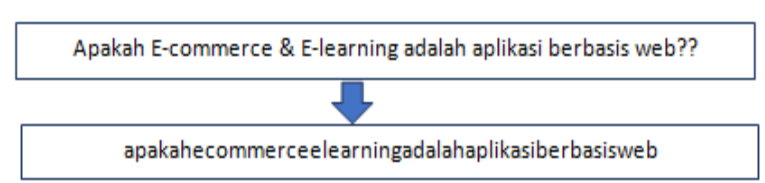

Gambar 3.2 contoh pengapusan karakter

\subsubsection{Pembentukan rangkaian n-gram.}

Proses pembentukan rangkaian $n$-gram pada algoritma winnowing dilakukan dengan cara memebentuk rangkaian karakter sepanjang $\mathrm{n}$ yang diambil dari hasil penghapusan karakter yang tidak diperlukan, rangkaian n-gram pertama kali dimulai dari karakter ke 1 sampai dengan karakter $\mathrm{n}$. Nilai $\mathrm{n}$ yang baik tidak terlalu kecil dan tidak terlalubesar (Syahputra, 2017). Berikut contoh bentuk nilai $\mathrm{n}$-gram dengan panjang $n=4$ :

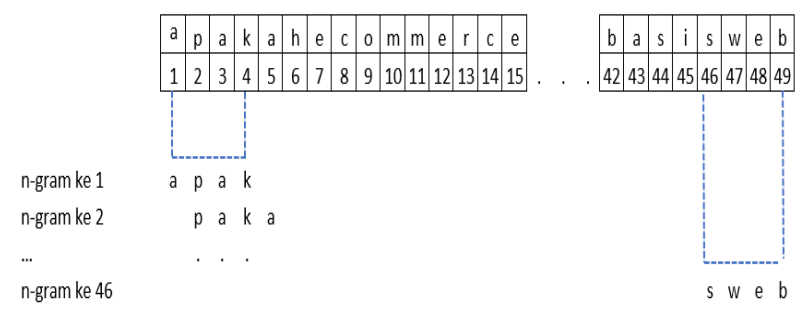

Contoh lain Hasil n-gram:

$\begin{array}{llll}\text { siste } & \text { istem } & \text { stemi } & \text { temin } \\ \text { eminf } & \text { minfo } & \text { infor } & \text { nform } \\ \text { forma } & \text { ormas } & \text { masi } & \text { masib } \\ \text { asibe } & \text { siber } & \text { iberb } & \text { berba } \\ \text { erbas } & \text { basi } & \text { basis } & \text { asisw }\end{array}$

3.2.2.3 Penghitungan nilai hash setiap n-gram. Algoritma winnowing menggunakan rolling hash untuk menghitung nilai hash masing-masing rangkaian gram.

Berikut rumus fungsi hash dan rolling hash

$H_{\left(C_{1} \ldots C_{n}\right)}=C_{1} * b^{(n-1)}+C 2 * b^{(n-2)}+\cdots+C_{(n-1)} *$

$b^{(n)}+C_{n}$

$H_{\left(C_{2} \ldots C_{(n+1)}\right)}=\left(H_{\left(C_{1} \ldots C_{n}\right)}-C_{1} * b^{(n-1)}\right) * b+C_{(n+1)}$

Dimana:

$H_{\left(C_{1} \ldots C_{n}\right)}=\quad$ Nilaihash

http://ejournal.urindo.ac.id/index.php/TI
$C_{1}=$ Nilai ASCII karakter ke -1 pada string

$n=$ Panjangstring

$b=$ nilai basis hash

Berikut contoh Hasil rolling hash

$\begin{array}{llll}83506 & 89554 & 88480 & 80035 \\ 84612 & 82591 & 84959 & 81129 \\ 86932 & 87990 & 83755 & 78213 \\ 88056 & 81084 & 77313 & 80407 \\ 86615 & 76880 & 78315 & 88589\end{array}$

3.2.2.4 Membagi ke dalam window.

Algoritma winnowing tidak menggunakan nilai hash yang dibentuk pada tahap sebelumnya akan dibagi ke dalamwindow berukuran w. berikut contoh pembentukan window dari hasil perhitungan nilai hash pada tahap sebelunya dengan ukuran lebarwindow $(w)=4$.

$\begin{array}{llll}W=4 & & & \\ 83506 & 89554 & 88480 & 80035 \\ 89554 & 88480 & 80035 & 84612 \\ 88480 & 80035 & 84612 & 82591 \\ 80035 & 84612 & 82591 & 84959 \\ 84612 & 82591 & 84959 & 81129 \\ 82591 & 84959 & 81129 & 86932 \\ 84959 & 81129 & 86932 & 87990 \\ 81129 & 86932 & 87990 & 83755 \\ 86932 & 87990 & 83755 & 78213 \\ 87990 & 83755 & 78213 & 88056 \\ 83755 & 78213 & 88056 & 81084\end{array}$

3.2.2.5 Pemilihan beberapa nilai hash menjadi document figerprinting.

Setelah terbentuk window seluruh nilai hash, tahap berikutnya yaitu dengan menentukan nilai fingerprint teks. Nilai fingerprintditentukan dengan memilih hash terkecil dari setiap window. Pemilihan nilai fingerprint dari hasil pembentukan window pada tahap sebelumnya.

$\begin{array}{llll}83506 & 89554 & 88480 & \mathbf{8 0 0 3 5} \\ 89554 & 88480 & \mathbf{8 0 0 3 5} & 84612 \\ 88480 & \mathbf{8 0 0 3 5} & 84612 & 82591 \\ \mathbf{8 0 0 3 5} & 84612 & 82591 & 84959 \\ 84612 & 82591 & 84959 & \mathbf{8 1 1 2 9} \\ 82591 & 84959 & \mathbf{8 1 1 2 9} & 86932 \\ 84959 & \mathbf{8 1 1 2 9} & 86932 & 87990\end{array}$

Maka fingerprint yang terbentuk yaitu

800358112978213773137688078315 
3.2.2.6 Persamaan jaccard Coeficient.

Nilai Fingerprint terbentuk dari algoritma winnowing digunakanuntuk mengukur prosentase tingkat kemiripan teks pada persamaan(Syahputra, 2017).

Adapun rumus persamaan jaccard Coeficient. similiarity $=\frac{\text { jumlah fingerprint sama }}{\text { Total seluruh fingerprint }} \times 100 \%$

3)

atau

$\operatorname{similiar}\left(d_{i}, d_{j}\right)=\frac{\left|w\left(d_{i}\right) \cap w\left(d_{i}\right)\right|}{\left|w\left(d_{i}\right) \cup w\left(d_{i}\right)\right|} \times 100 \% \ldots$

Dengan nilai $d_{i}$ nilai- nilai fingerprintpada teks, $d_{j}$ nilai-nilai fingerprint pada teks $w\left(d_{i}\right) \cap w\left(d_{i}\right)$ jumlah nilai fingerprint yang sama antara teks ke -I dan teks ke-j dan $w\left(d_{i}\right) \cup$ $w\left(d_{i}\right)$ adalah total nilai fingerprint teks ke-i dan teks ke-j.

\subsection{Alur Penelitian}

Desain penelitian ini mengikuti siklus action research, Langkah-langkah dalam action research menurut Baskervile dalam lee(2007), yaitu Diagnosing, action planning, action taking, evaluating, dan reflection.

\section{a. Diagnosing}

Tahap ini merupakan proses identifikasi masalah - masalah yang menjadi dasar penelitian tentang deteksi dini kemiripan judul tugas akhir. Pada tahap ini juga dilakukan proses pengumpulan data, data yang dikumpulkan adalah data primer dan data sekunder. Data primer diperoleh melalui observasi secara langsung yaitu dengan melakukan observasi ke STMIK AMIKOM fokus pada unit akademik yang menangani pengajuan judul tugas akhir sedangkan data sekunder diperoleh melalui studi literatur dengan menggali informasi jurnal penelitian terbaru tentang deteksi kemiripan judul Tugas akhir.

\section{b. Action Planning}

Tahap ini merupakan proses penyusunan rencana tindakan yang tepat guna menyelesaikan permasalahan pada penelitian ini. Tindakan Tindakan yang direncanakan meliputi penerapan kaidah String Matching dan Winnowing. Tahap ini juga membahas desain sistem yang akan diterapkan. Desain yang digunakan uuntuk alur sistem menggunakan Flow chart.

c. Action Taking

Tahap ini merupakan tahapan implementasi desain pada tahap Action planning ke dalam program atau aplikasi guna melakukan perhitungan atau pembobotan..

d. Evaluation

Tahap ini merupakan tahapan dimana sistem diuji secara menyeluruh. Tujuan utama dari pengujian sistem adalah untuk memastikan bahwa integrasi antar modul aplikasi telah memenuhi spesifikasi kebutuhan dan berjalan sesuai dengan skenario pengujian, kemudian menguji dengan masukkan tertentu yang diharapkan menghasilkan keluaran yang sesuai.

e. Reflection

Tahap ini merupakan bagian akhir siklus yang telah dilaluidengan melaksanakan review tiap tahapdalam penelitian ini penelitian dapat berakhir. AdapunLangkah-langkah dalam action research seperti terlihat dallam gambar dibawah ini.

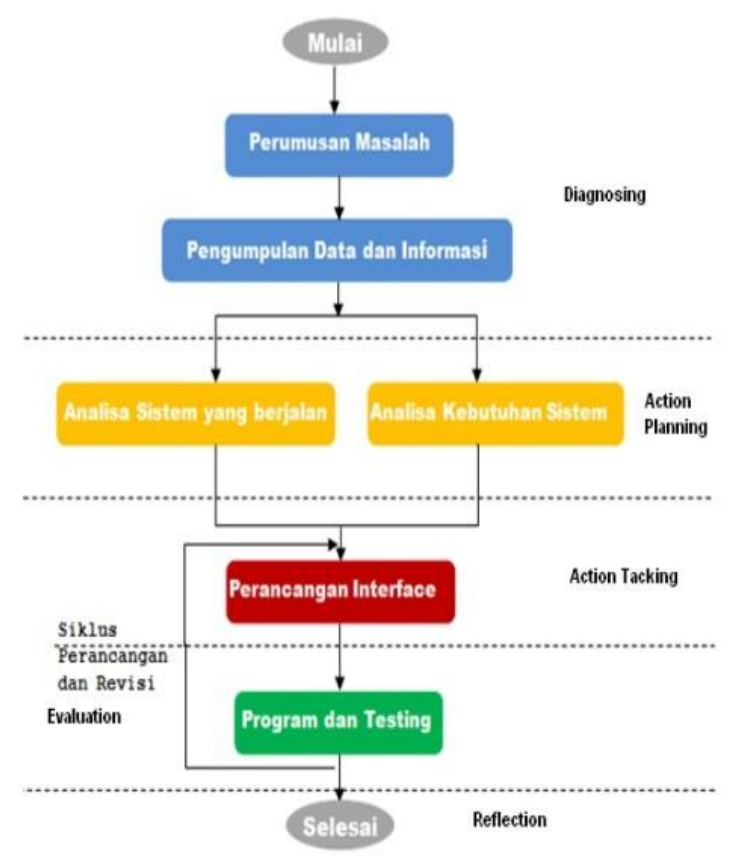

Gambar 3.3 alur penelitian 


\section{HASIL}

\subsection{Action Planning}

Pada tahapan ini penulis akan menguraikan analisa kinerja kedua metode string matchingdan winnowing dari sini akan diketahui cara kerja dari kedua metode tersebut dalam memecahkan sebuah permasalahan.

\subsubsection{String matching}

Menurut (Sinaga et al., 2016)String matching adalah proses pencarian semua kemunculan query yang selanjutnya disebut Pattern ke dalam string yang lebih panjang.string matching dirumuskan dengan :

$$
\begin{aligned}
& x=x[0 \ldots m-1] \\
& y=y[0 \ldots n-1]
\end{aligned}
$$

Dimana:

$$
\begin{aligned}
& \mathrm{x}=\text { Pattern } \\
& \mathrm{m}=\text { panjang Pattern } \\
& \mathrm{y}=\text { teks } \\
& \mathrm{n}=\text { panjang teks }
\end{aligned}
$$

Dalam pencocokan string ini penulis menggunakan algoritma Knout Morris Pratt. dimana cara kerja algoritma ini pencocokan string dengan menggunakan Pattern $(0 . . n-1)$ atau string pendek, kemudian dicocokkan dengan string yang lebih panjang disebut dengan teks (0..m-1). Pencocokan antara Pattern dan teks dilakukan dengan menggeser indeks Pattern sampai indeks terakhir, apabila dalam pergeseran Pattern terhadap teks terdapat kemiripan maka proses pergerseran dihentikan dan dinyatakan cocok.

\subsubsection{Pemindaian Teks}

Dalam algoritma string matching tahapan pertaman yaitun dengan Memindaiteksdenganbantuansebuahwindowyan gukurannyasamadengan panjang Pattern. Dicontohkan algoritma Knouth morris pratt dalam pencocokan
Patern $=$ JUAL

Teks1= SISTEMINFORMASI BERBASIS WEB

Teks1=KOMPUTERISASI PENJUALAN

$$
\text { BERBASIS WEB }
$$

Teks1=LAPORAN LABA-RUGI PADA RUMAH

$$
\text { MAKAN }
$$

4.1.1.2 Menempatkanwindow pada awal teks. Langkah berikutnya yaitu pencocokan digambarkan pada tabel 4.1 dibawah ini. Dimana data Pattern dan teks ditempatkan kedalam window yang nantinya akan dilakukan pergeseran atau dengan istilah sliding window.

Tabel 4.1 langkah ke 1

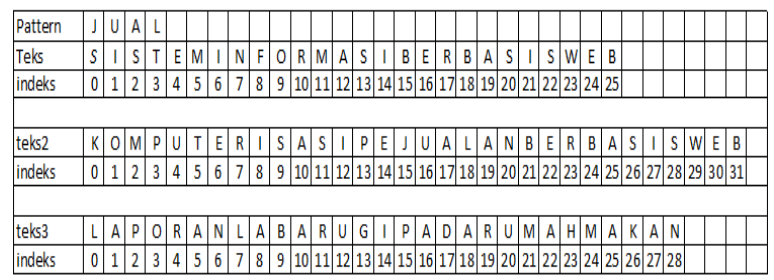

\begin{tabular}{|c|c|c|c|c|c|c|c|c|c|c|c|c|c|c|c|c|c|c|c|c|c|c|}
\hline Pattern & & 10 & A & & & & & & & & & & & & & & & & & & & \\
\hline Teks & \begin{tabular}{l|l}
$s$ & 1 \\
\end{tabular} & 15 & $T$ & $\mathrm{E} N \mathrm{~N}$ & $\mathrm{M} 1$ & $\mathrm{~N}$ & $F$ & $\begin{array}{ll}0 & R \\
\end{array}$ & $M$ & A S & \begin{tabular}{l|l}
$S$ & 1 \\
\end{tabular} & \begin{tabular}{|l|l|}
$B$ & $E$ \\
\end{tabular} & \begin{tabular}{|l|l|}
$E$ & $R$ \\
\end{tabular} & \begin{tabular}{|l|l}
$B$ & $A$ \\
\end{tabular} & $s$ & & w & \begin{tabular}{|l|l}
$E$ & $B$ \\
\end{tabular} & & & & \\
\hline indeks & \begin{tabular}{l|l} 
& 1 \\
\end{tabular} & 1 & 3 & 4 & 5 & 7 & 8.5 & \begin{tabular}{l|l|l}
9 & 10 \\
\end{tabular} & $0 \mid 11$ & \begin{tabular}{|l|l}
12 & 1 \\
\end{tabular} & $13 \mid 14$ & \begin{tabular}{|l|l|}
15 & 16 \\
\end{tabular} & \begin{tabular}{ll|}
16 & 17 \\
\end{tabular} & \begin{tabular}{l|l}
18 & 19 \\
\end{tabular} & 202 & & 23 & 2425 & & & & \\
\hline teks2 & $\begin{array}{lll}k & 0 \\
\end{array}$ & $0 \mid \mathrm{M}$ & $P$ & $\begin{array}{lll}01 \\
\end{array}$ & \begin{tabular}{l|l}
$T$ & .
\end{tabular} & R & 118 & \begin{tabular}{l|l|}
$S$ & $A$
\end{tabular} & $|s|$ & $1 \mathrm{P}$ & $P \mid E$ & 10 & $U \mid A$ & \begin{tabular}{l|l} 
& $A$
\end{tabular} & $\mathrm{~N}$ & \begin{tabular}{l|l|l}
$B$ & $E$
\end{tabular} & $R$ & \begin{tabular}{l|l|l}
$B$ & A
\end{tabular} & \begin{tabular}{l|l}
$S$ & I
\end{tabular} & $1 \mathrm{~S}$ & $|W| E$ & $B$ \\
\hline indeks & & $\begin{array}{ll}12 \\
\end{array}$ & 3 & 45 & 56 & 7 & 85 & \begin{tabular}{l|l|}
9 & 10 \\
\end{tabular} & $0 \mid 11$. & & & & & & & & & & & & & \begin{tabular}{l|l|l|}
0 & 31
\end{tabular} \\
\hline & & & & & & & & & & & & & & & & & & & & & & \\
\hline teks3 & L & & 0 & $\mathrm{R}$ & \begin{tabular}{l|l}
$\mathrm{A}$ & $\mathrm{N}$ \\
\end{tabular} & L & A & \begin{tabular}{l|l|} 
& $A$ \\
\end{tabular} & $R$ & $U C$ & $\begin{array}{lll}G & 1 \\
\end{array}$ & \begin{tabular}{l|l} 
& $A$ \\
\end{tabular} & \begin{tabular}{ll|l}
$A$ & $D$ \\
\end{tabular} & \begin{tabular}{l|l}
$A$ & $R$ \\
\end{tabular} & U & $\begin{array}{ll}M & A\end{array}$ & $\mathrm{H}$ & $\begin{array}{ll}M & A \\
\end{array}$ & \begin{tabular}{|l|l} 
& $A$ \\
\end{tabular} & \begin{tabular}{l|l}
$A$ & $N$
\end{tabular} & & \\
\hline indeks & . & & 3 & \begin{tabular}{|l|l} 
\\
\end{tabular} & & 7 & 8 & \begin{tabular}{l|l|l}
9 & 10 \\
\end{tabular} & 11 & 121 & & \begin{tabular}{|l|l|}
15 & 16 \\
\end{tabular} & & \begin{tabular}{|l|l|}
18 & 19 \\
\end{tabular} & 20 & & & & & $27 \sqrt[28]{2}$ & & \\
\hline
\end{tabular}

\subsubsection{Sliding} windowMembandingankarakterpadawindowden gankarakterdari Pattern.Setelah pencocokandilakukanpergeserankekananpadawi ndow.

Tabel 4.2 langkah ke 2

Posedur ini di lakukan secara berulang-ulang secara berkelanjutan sampai dengan panjang teks atau istilah dalam dalam rumus simbol $n=$ length menyatakan panjang teks.

Tabel 4.3 langkah ke 3

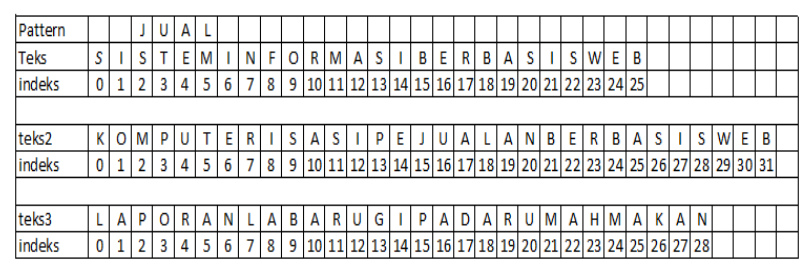

Tabel 4.4 langkah ke 15 


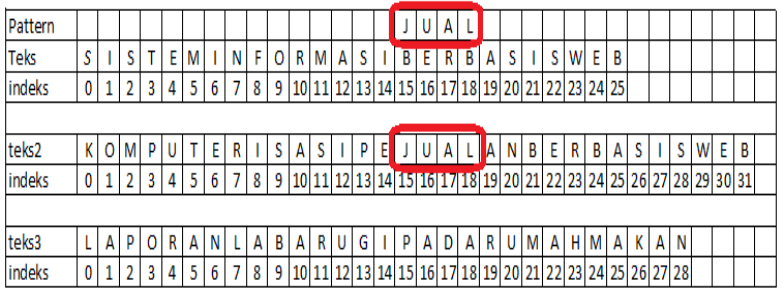

Prosedurinidilakukanberulang-

ulangsampaiwindowberadapadaakhirteks.

Diketahui pada iterasi ke 15di temukan dokumen teks yang sama maka iterasi berhenti di teks tersebut dan menyimpan data tersebut sembari melakukan sliding window ke dokumen teks berikutnya.

\subsubsection{Algoritma winnowing}

Algoritma winnowing merupakan salah satu algoritma yang berfungsi sebagai document fingerprint atau algoritma yang digunakan untuk mendeteksi tindakan plagiarisme dengan menggunakan teknik hashing. Input dari algoritma winnowing berupa dokumen teks, dan akan menghasilkan keluaran berupa kumpulan nilai hash yang terbentuk dari peritungan ASCII pada setiap karakter. Dari nilai hash tersebutnantinya akan digunakan sebagai fingerprint untuk mendeteksi adanya suatu plagiarisme(Sunardi et al., 2018).

\subsubsection{1 white insensitivity}

dalam white insensivity dalam algoritma winnowing proses yang akan dikerjakan pada sebuah data kalimat ataupun sebuah judul tugasakhiryaitu dengan ignore case dimana dalam kalimat atau judul sebuah Tugas akhir yang terdapat huruf kapital akan disesuaikan atau dengan istilah lain diseragamkan, setelah itu menhilangkan karakter yang tidak dibutuhkan misal tanda baca, spasi dan karakter-karakter yang tidak relevan lainya.dimisalkan terdapat judul tugas akhir:

\section{"Sistem Informasiberbasis web"}

maka kalimat tersebut akan diubah menjadi:

\section{"sisteminformasberbasisweb"}

Atau Bisa dirubah menjadi

\section{"SISTEMINFORMASIBERBASISWEB"}

\subsubsection{Pembentukan Rangkaian N-gram}

Setelah kalimat tersebut dibersihkan maka langkah selanjutnya membentuk rangkaian ngram dengan ukuran tertentu dimisalkan ukran 5-grammenjadi:

\section{siste istemstemi temin eminf minfo infor nformformaormas rmasi masibasibe siber iberb berba erbas rbasi basis asisw siswe isweb}

\subsubsection{Hashing}

Hashing merupakan suatu cara untuk menstransformasikan sebuah string menjadi suatu nilai yang unik dengan mengelompokkan kumpulan karakter (string) dengan panjang tertentu(fixed-length), hal ini dilakukan dangan tujuan memberi penanda dari string tersebut. Fungsi yang dihasilkan pada proses ini disebut dengan fungsi hash, sedangkan nilai yang dihasilkandisebut nilai hash.

Algoritma winnowing menggunakan rolling hash untuk menghitung nilai hash masing- masing rangkaian gram. Fungsi hash dengan rolling hashdidefinisikan pada persamaan.

$$
\begin{gathered}
H_{\left(C_{1} \ldots C_{n}\right)}=C_{1} * b^{(n-1)}+C 2 * b^{(n-2)}+\cdots+ \\
C_{(n-1)} * b^{(n)}+C_{n} \ldots \ldots \ldots \ldots \ldots \ldots \ldots \ldots \ldots \ldots \ldots \ldots \ldots \ldots \ldots \ldots \ldots \ldots \ldots \ldots \\
\end{gathered}
$$

Dengan $\mathrm{C}$ adalah nilai ascii suatu karakter, $\mathrm{b}$ atau basis merupakan bilangan prima(tidak ditentukan) dan $\mathrm{n}$ adalah banyaknya karakteratau panjang rangkaiann-gram.

Untuk nilai hash kedua dan selanjutnya perhitungan tidak perlumelakukaniterasi dari indeks pertama sampai terakhir. Perhitungan nilai $\operatorname{hashH}_{\left(C_{1} \ldots C_{n}\right)}$ dapat dilakukan dengan cara:

$$
\begin{aligned}
& H_{\left(C_{2} \ldots C_{(n+1)}\right)}=\left(H_{\left(C_{1} \ldots C_{n}\right)}-C_{1} * b^{(n-1)}\right) * \\
& b+C_{(n+1)}
\end{aligned}
$$

Misalnya perhitungan nilai hash pada rangkaian n-gram "siste" dan "istem" (tanpa tanda petik) dengan nilai basis $(b)=5$, panjang rangkaian $n$ $\operatorname{gram}(n)=5$.

$$
\begin{gathered}
H_{(s i s t e)}=\operatorname{ascii}(s) * 5^{(4)}+\operatorname{ascii}(i) * 5^{(3)} \\
+\operatorname{ascii}(s) * 5^{(2)}
\end{gathered}
$$




$$
\begin{gathered}
+\operatorname{ascii}(t) * 5^{(1)}+\operatorname{ascii}(e) \\
=115 * 625+105 * 125+115 * 25+116 * 5+101 \\
=88556 \quad \operatorname{ascii}(s) * 5^{(4)}+\operatorname{ascii}(i) * 5^{(3)} \\
+\operatorname{ascii}(s) * 5^{(2)} \\
H_{(i s t e m)} \\
+\operatorname{ascii}(t) * 5^{(1)}+\operatorname{ascii}(e) \\
=105 * 625+115 * 125+116 * 25+101 * 5+109 \\
=83514
\end{gathered}
$$

Dengan menggunakan hasil pembentukan rangkaian-rangkaian $\mathrm{n}$-gram sebelumnya, dengan menggunakan basis $(b)=5$ dan panjang $n$-gram $(n)=5$, perhitungan hash yaitu:

$\begin{array}{llllll}88556 & 83514 & 89550 & 88485 & 80027 & 84621 \\ 83748 & 78216 & 88069 & 81068 & 77312 & 80425\end{array}$

4.1.2.4 Pembentukan window dari nilai hash Algoritma winnowing tidak menggunakan semua nilai hash dari setiap rangkaian gram yang dibentuk pada tahap sebelumnya akan dibagi ke dalam window berukuran w. Window pertama berisi nilai hash ke $-\mathrm{w}+1$ dan seterusnya sampai terbentuk window dari seluruh nilai hash. Pembentukan window dari hasil perhitungan nilai hash pada tahap sebelumnya dengan ukuran lebar window $(\mathrm{w})=4$ yaitu:

$\begin{array}{lllll}\text { window ke 1 } & 88556 & 83514 & 89550 & 88485 \\ \text { windowke 2 } & 83514 & 89550 & 88485 & 80027 \\ \text { windowke 3 } & 89550 & 88485 & 80027 & 84621 \\ \text { Window ke 4 } & 88485 & 80027 & 84621 & 82594 \\ \text { window ke 5 } & 80027 & 84621 & 82594 & 84954 \\ \text { window ke 6 } & 84621 & 82594 & 84954 & 81117 \\ \text { window ke 7 } & 82594 & 84954 & 81117 & 86950 \\ \text { window ke 8 } & 84954 & 81117 & 86950 & 87980 \\ \text { window ke 9 } & 81117 & 86950 & 87980 & 83748 \\ \text { window ke 10 } & 86950 & 87980 & 83748 & 78216 \\ \text { window ke 11 } & 87980 & 83748 & 78216 & 88069 \\ \text { window ke 12 } & 83748 & 78216 & 88069 & 81068 \\ \text { window ke 13 } & 78216 & 88069 & 81068 & 77312 \\ \text { window ke 14 } & 88069 & 81068 & 77312 & 80425 \\ \text { window ke 15 } & 81068 & 77312 & 80425 & 86605 \\ \text { window ke 16 } & 77312 & 80425 & 86605 & 76890 \\ \text { window ke 17 } & 80425 & 86605 & 76890 & 78319 \\ \text { window ke 18 } & 86605 & 76890 & 78319 & 88571\end{array}$

window ke $19 \quad 76890 \quad 78319 \quad 88571 \quad 83578$

4.1.2.5 Pemilihan Fingerprint dari setiap window Setelah terbentuk window dari seluruh nilai hash, maka tahap selanjutnya adalah menentukan nilai Fingerprint teks. Nilai fingerprint ditentukan denganmemilih nilai hash terkecil dari setiap window. Pemilihan nilai fingerprint dari hasil pembentukan window pada tahap sebelumnya yaitu:

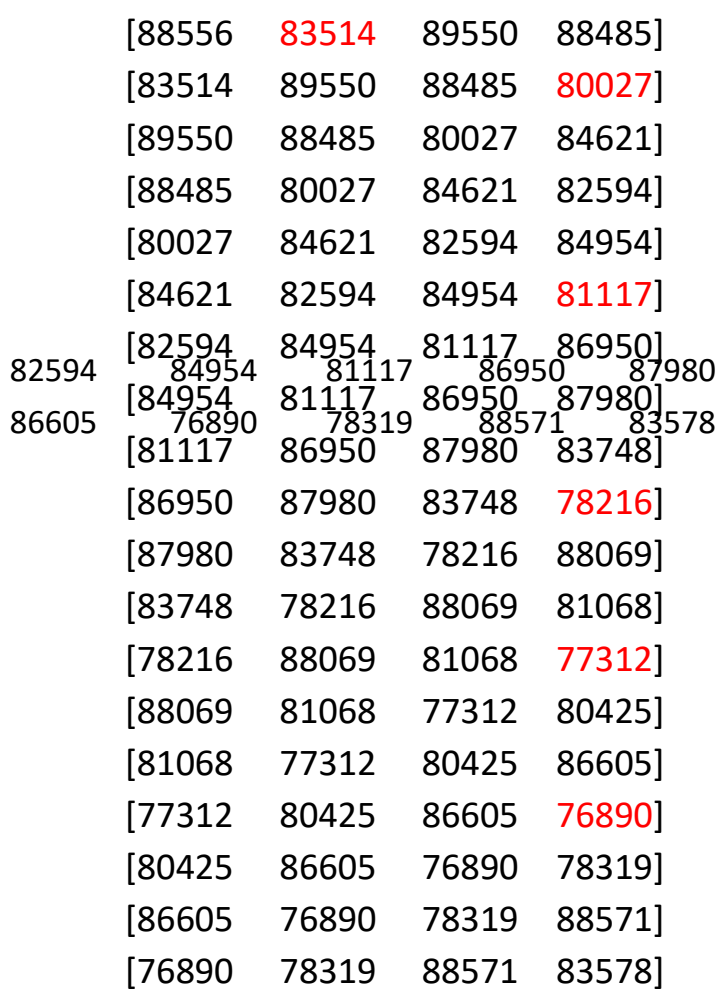

4.1.2.6 Persamaan Jaccard Coeficient

Nilai Fingerprint terbentuk dari algoritma winnowing digunakanuntuk mengukur prosentase tingkat kemiripan teks pada persamaan(Syahputra, 2017).

Adapun rumus persamaan jaccard Coeficient.

$$
\begin{aligned}
& \text { similiarity } \\
& =\frac{\text { jumlah fingerprint sama }}{\text { Total seluruh fingerprint }} \times 100 \%
\end{aligned}
$$

Dari persamaan ini akan diambil jumlah nilai fingerprint yang sama dan dibagi dengan total nilai fingerprint maka bisa dihitung tingkat kemiripanya dengan derajat prosentase(\%).

Dimana nilai fingerprintdiperoleh dari dua judul Tugas Akhir yang berbeda yang dihitung tingkat 
kemiripanya dengan menggunakan algoritma winnowing.

\section{Judul1 = sisteminformasiberbasisweb \\ Judul2 =sistempenjualanberbasisweb}

Berikut hasil penghitungan kemiripan dengan rumus jaccard Coeficient

$\begin{array}{lllllll}\text { fingerprint1 } & 83514 & 80027 & 81117 & 78216 & 77312 & 76890\end{array}$

$\begin{array}{lllllll}\text { fingerprint2 } & 83514 & 80165 & 80207 & 77323 & 77312 & 76890\end{array}$

$$
\begin{gathered}
\text { similiarity }=\frac{6}{12} \times 100 \% \\
=50 \%
\end{gathered}
$$

Berdasarkan perhitungan tingkat kemiripan kedua judul tugas akhir yang diterjemahkan ke dalam nilai fingerprint menggunakan algoritma winnowing maka kemiripan antara judul 1 dengan judul2 memiliki tingkat kemiripan sebesar $50 \%$.

\section{KESIMPULAN}

Analisa algoritma antara string matching dan winnowing untuk deteksi kemiripan judul Tugas Akhir telah dapat dilakukan dengan mengetahui kinerja kedua algoritma tersebut. Hasil penelitian sebagai berikut:

1. Hasil pengujian kemiripan judul dengan menggunakan string matching dengan algoritma Knout Morris Pratt berhasil menentukan kemiripan string atau teks

2. Untuk efektifitas algoritma string matching tingkat kemiripannya belum terlihat jelas dalam derajat prosennya(\%).

3. Algoritma String matching lebih efisien dalam proses penghitungan jika dibandingkan dengan Algoritma Winnowing.

4. Algoritma winnowing untuk proses penghitunganya labih komplek jika dibandingkan dengan algoritma string matching.

5. Kelebihan algoritma winnowing yaitu bisa menghitung secara otomatis tingkat kemiripanya dalam bentuk prosentase.

\section{DAFTAR PUSTAKA}

1. Astutik, S., Cahyani, A. D., \& Sophan, M. K. (2014). Sistem Penilaian Esai Otomatis Pada E-Learning Dengan Algoritma Winnowing. Jurnal Informatika, 12(2), 47-52. https://doi.org/10.9744/informatika.12.2 .47-52

2. Effendi, D., Hartono, T., \& Kurnaedi, A. (2013). Penerapan String Matching Menggunakan Algoritma Boyer-Moore Pada Translator Bahasa Pascal Ke C. Majalah Ilmiah UNIKOM, 11(2), 262275.

3. Hasibuan, Z. A. (2007). Metodologi Penelitian Pada Bidang Ilmu Komputer Dan Teknologi Informasi. Konsep, Teknik, Dan Aplikasi, Universitas Indonesia, 194.

4. Sinaga, J. I., Mesran, M., \& Buulo, E. (2016). Aplikasi Mobile Pencarian Kata Pada Arti Ayat Al-Qur' an Berbasis Android Menggunakan ... Jurnal INFOTEK, II(Juni 2016), 68-72.

5. Sunardi, S., Yudhana, A., \& Mukaromah, I. A. (2018). Implementasi Deteksi Plagiarisme Menggunakan Metode NGram Dan Jaccard Similarity Terhadap Algoritma Winnowing. Transmisi, 20(3), 105.

https://doi.org/10.14710/transmisi.20.3. 105-110

6. Syahputra, A. R. (2017). Implementasi Algoritma Winnowing Untuk Deteksi Kemiripan Judul Skripsi Studi Kasus: STMIK Budi Darma. Pelita Informatika Budi Darma, 12(1), 1-9.

7. Waruwu, F. T., \& Mandala, R. (2016). Perbandingan Algoritma Knuth Morris Pratt dan Boyer Moore Dalam Pencocokan String Pada Aplikasi 
Kamus Bahasa Nias. Jurnal Ilmiah

INFOTEK, 1(1), 36-43. 